\title{
Utilization of Family Planning Methods Among Postpartum Mothers in Kailali District, Nepal
}

This article was published in the following Dove Press journal:

International Journal of Women's Health

\author{
Arun Kumar Joshi ${ }^{1}$ \\ Dipak Prasad Tiwari ${ }^{2}$ \\ Anil Poudyal ${ }^{3}$ \\ Namuna Shrestha (D) \\ Uttam Acharya $\mathbb{D}^{4}$ \\ Govinda Prasad Dhungana $\mathbb{D}^{5}$ \\ 'Chitwan Medical College, Chitwan, \\ Nepal; ${ }^{2}$ Ministry of Health and \\ Population, Kathmandu, Nepal; ${ }^{3} \mathrm{Brac}$ \\ University, Dhaka, Bangladesh; ${ }^{4} \mathrm{Global}$ \\ Health Program, Thammasat University, \\ Bangkok, Thailand; ${ }^{5}$ Department of \\ Community Medicine and Public Health, \\ Chitwan Medical College, Chitwan, Nepal
}

Correspondence: Arun Kumar Joshi

Email arunjoshilI@gmail.com
Background: Postpartum contraceptives use offers a distinctive opportunity to maintain appropriate birth spacing for health benefits to both mother and child. However, the concept of postpartum family planning (PPFP) is poorly understood and contraceptives use during the postpartum period remains low in Nepal. Therefore, this study aimed to assess the factors affecting the utilization of family planning (FP) methods among postpartum mothers in the Kailali district, Nepal.

Methods: A community-based cross-sectional study was conducted between September and October 2013 among postpartum mothers in Kailali district. Simple random sampling was applied to select a total of 427 study participants. A pre-tested standard semi-structured questionnaire was used for gathering data. Data were analyzed using Statistical Package for Social Sciences (SPSS) version 20.0.

Results: Overall, $32.8 \%$ of the postpartum women used different types of contraceptives. Condoms (37.1\%) followed by Depo-Provera $29.3 \%$ were the most used postpartum contraceptives. Half $(50 \%)$ of the postpartum women had an unmet need for family planning. Multiple logistic regression model revealed that the occupation of husband $[\mathrm{AOR}=3.2(95 \%$ CI: 2.0-6.00], past use of family planning methods [AOR=4.0 (95\% CI:2.4-6.5)] and resumption of menstruation $[\mathrm{AOR}=2.5(95 \% \mathrm{CI}: 1.6-4.1)]$ were significantly associated with the use of modern contraceptives during the first year of the postpartum period.

Conclusion: Contraceptive uptake within the first year of postpartum was found to be low among women in the Kailali district, Nepal. Previous experience with the use of family planning methods, occupation of the husbands, and resumption of menstruation are important factors in the PPFP decisions of women in this population. Therefore, the family planning program should work on improving couples' knowledge of the risk of pregnancy, fertility returning time and modern contraceptives use during the postpartum period targeting women whose husbands are in migrant occupations, who are not menstruating and who have not used FP before.

Keywords: postpartum, family planning, contraception, Nepal

\section{Introduction}

Family planning (FP) is widely acknowledged as an effective intervention for saving women's and children's lives and improving their health. ${ }^{1,2}$ The periods of pregnancy and immediately after delivery are considered great opportune for counseling women on the adoption of modern family planning methods because of the woman's frequent encounter in the health system over a relatively long time horizon. ${ }^{3}$ It has been observed that closely spaced pregnancies within the first year postpartum are the riskiest for mother and children, resulting in increased risks for adverse outcomes. ${ }^{4}$ 
Government of Nepal (GoN), Family Welfare Division (FWD) has been promoting PPFP services to address the FP need of postpartum mothers in Nepal. However, due to various supply-side barriers and limited knowledge of PPFP among clients, the utilization of modern contraceptive immediately after birth remains low in Nepal. ${ }^{5}$ The low uptake of FP method is largely depending on many factors. ${ }^{6,7}$ A study conducted in Nepal reported that more than one-quarter of women who gave birth in the last five years became pregnant within 24 months of giving birth and $52 \%$ had an unmet need for family planning within 24 months postpartum. ${ }^{8}$ Hence, the introduction of an effective contraceptive method during the postpartum period is very crucial. So this study aims to assess the factors affecting the utilization of FP methods among postpartum mothers in the Kailali District.

\section{Methods}

A community-based cross-sectional study was conducted between September and October, 2013 at four selected Village Development Committees (VDCs) namely Darakh, Durgauli, Kotatulsipur, and Pahalmanpur of Kailali districts. The eligible women for this study were those married women having a child less than one-yearold. In this study postpartum family planning (PPFP) considered as the prevention of unintended and closely spaced pregnancy through the first twelve months following childbirth. The PPFP use referred to the current status of using any modern contraceptive methods or treatment of involuntary fertility after the recent childbirth.

The lottery method was used to select four VDCs randomly out of 42 . By taking a prevalence of $22 \%$ postpartum contraceptive utilization from Nepal Demographic and Health Survey (NDHS) at $95 \%$ confidence interval (CI), $15 \%$ allowable error of prevalence, and addition of a non-response level of $5 \%$ the total sample size required was determined to be 427 . The list of married women $(\mathrm{N}=1244)$ who had delivered a child within the last year obtained from immunization register of local health facilities of each VDC which became the sampling frame. To determine the required number of samples to be taken from each VDC, at first population percentage occupied by married women who had delivered a child with the last year from each VDCs among total population $(\mathrm{N}=1244)$ was calculated. After that, the same percentage of the population was identified within the particular VDC to calculate the required number of samples from the particular VDC (Darakh-127, Durgauli-103, Kotatulsipur-
93, Pahalmanpur-104). The lottery method was applied to select the required number of respondents in each VDCs.

The semi-structured questionnaire was developed by reviewing similar study literature and the Demographic and Health Survey questionnaire. Pretesting of the questionnaire was carried out in Shivanagar VDC of Chitwan district in a $10 \%$ sample of the similar women having a child less than one year of age and necessary changes made following pretesting. Data collection was done by house to house survey using a semi-structured questionnaire and face to face interview. The enumerators visited the selected household to collect the data and data collection was done until the required sample size was met.

The study was carried out following the principles of the Declaration of Helsinki. The ethical principles of respect, beneficence, and justice were maintained throughout the data-collection process. Ethical clearance was sought and obtained from the Tribhuwan University, Chitwan Medical College Ethical Review Committee (CMC-IRC). Approval from the District Public Health Office and respective VDCs offices were also obtained before collecting data. Written informed consent was obtained from each participant.

In this study, the primary outcome, postpartum family planning method use was captured through women's response. Key maternal and household variables as a predictor of postpartum FP method use were included in the analysis: ethnicity as Dalit, Janjatis and Others, education of mother as illiterate, read and write, primary schooling, secondary schooling, and SLC and above, occupation of a mother as housewives and engaged with work, husband's occupation as migrant workers and other, husband education as illiterate and SLC and above, ANC visit, ANC counseling received, past FP use, Use of media, PNC visit and PNC counseling received dichotomized as yes or no. The reference variables were coded 1 while doing bivariate and multivariate analysis.

Data were entered using SPSS version 16.0 and exported to SPSS version 20.0 statistical software for further analysis. The family planning knowledge assessment tool was 12 sets of questions used to assess the knowledge of participants on FP methods. ${ }^{9,10}$ Question assessing knowledge on FP methods were assigned scores using predetermined cut-off values. Hundred points were allocated to 12 questions to assess their knowledge about postpartum family planning. The postpartum mothers were categorized into good ( $>60)$, satisfactory (41-60) and poor $(<40)$ on levels of overall knowledge. Association between 
independent variables and the utilization of postpartum family planning methods were assessed using the chisquared test and bivariate logistic regression. Those variables significantly associated in the bivariate analysis ( $\mathrm{p}<0.05$ at $95 \%$ C.I.) were further subjected to multivariate analysis to evaluate the relationship between a group of predictor variables and postpartum family planning method use.

\section{Results}

\section{Socio-Demographic Characteristics of the Study Population}

A total of 427 participants were interviewed. The mean age of the participants was 23.7 with a standard deviation of 4.5. Among the total participants, more than half of the participants (58.3\%) were Disadvantages Janjatis, 16.2\% were Dalits, and $16.4 \%$ belonged to Upper Caste. Regarding religion, the majority $(97.7 \%)$ of the participants were Hindus. Similarly, $31.1 \%$ of the participants had primary education, $21.3 \%$ of the participants could read and write but never attended school and $14.8 \%$ were illiterate. Regarding the education of the husband, $35.1 \%$ had primary education followed by secondary education $(26.2 \%)$ and $7 \%$ of the husbands were found illiterate. Among the study participants, $67.7 \%$ were housewives, and $21.3 \%$ mentioned agriculture as their main occupation. Regarding the occupation of husband, $36.1 \%$ were migrant workers, $25.8 \%$ were farmers and $10 \%$ were engaged in some kind of service (Table 1).

\section{Reproductive and Service Related Characteristics of the Participants}

Among the participants, $79.1 \%$ had one to two children. About $43 \%$ of the participants used family planning methods in the past years. When asked about their intention for a child in the future, about $37 \%$ of the mother had the intention of having another child. The utilization of antenatal care (ANC) service was very good as $93.2 \%$ of the mothers reported using ANC service during their pregnancy. Out of them, 56\% have received counseling about FP during those visits. Similarly, $49.4 \%$ of participants received postnatal care (PNC) service and $60.2 \%$ of them received PNC counseling on family planning (Table 2).

Participant's knowledge of the FP method was assessed using a scoring tool adapted from a similar study. The participant's knowledge of the FP method was categorized as good, satisfactory, and poor based on the score received
Table I Socio-Demographic Characteristics of the Participants

\begin{tabular}{|c|c|c|}
\hline Characteristics $(n=427)$ & $\mathbf{n}$ & $\%$ \\
\hline \multicolumn{3}{|l|}{ Age (Years) } \\
\hline$\leq 19$ & 47 & 11.0 \\
\hline $20-24$ & 224 & 52.5 \\
\hline $25-29$ & 108 & 25.3 \\
\hline$\geq 30$ & 48 & 11.2 \\
\hline \multicolumn{3}{|l|}{ Mean age: $23.7 \pm 4.5\left(S D^{\mathrm{a}}\right)$} \\
\hline \multicolumn{3}{|l|}{ Ethnicity } \\
\hline Disadvantaged janjati & 249 & 58.3 \\
\hline Upper caste & 70 & 16.4 \\
\hline Dalit & 69 & 16.2 \\
\hline Relatively advantaged janjati & 32 & 7.5 \\
\hline Disadvantaged non dalit tarai & 5 & 1.2 \\
\hline Religious minority & 2 & 0.5 \\
\hline \multicolumn{3}{|l|}{ Religion } \\
\hline Hindu & 417 & 97.7 \\
\hline Christian & 5 & 1.2 \\
\hline Buddhist & 3 & 0.7 \\
\hline Muslim & 2 & 0.5 \\
\hline \multicolumn{3}{|l|}{ Education of the participant } \\
\hline Illiterate & 63 & 14.8 \\
\hline General read and write & 91 & 21.3 \\
\hline Primary schooling & 133 & 31.1 \\
\hline Secondary Schooling & 79 & 18.5 \\
\hline $\mathrm{SLC}^{\mathrm{b}}$ and above & 61 & 14.3 \\
\hline \multicolumn{3}{|l|}{ Husband's education } \\
\hline Illiterate & 30 & 7.0 \\
\hline General read and write & 72 & 16.9 \\
\hline Primary schooling & 150 & 35.1 \\
\hline Secondary Schooling & 112 & 26.2 \\
\hline $\mathrm{SLC}^{\mathrm{b}}$ and above & 63 & 14.8 \\
\hline \multicolumn{3}{|l|}{ Occupation of the participant } \\
\hline Housewives & 289 & 67.7 \\
\hline Self employed & 125 & 29.3 \\
\hline Service & 13 & 3.0 \\
\hline \multicolumn{3}{|l|}{ Occupation of husband } \\
\hline Migrant worker & 154 & 36.1 \\
\hline Agriculture & 110 & 25.8 \\
\hline Self employed & 117 & 27.4 \\
\hline Service & 46 & 10.8 \\
\hline
\end{tabular}

Notes: ${ }^{\mathrm{a}} \mathrm{SD}$, standard deviation; ${ }^{\mathrm{b}} \mathrm{SLC}$, school leaving certificate.

by participants. Among the total participants $42.4 \%$ had good knowledge of family planning methods followed by $35.4 \%$ had satisfactory knowledge and $22.2 \%$ had poor knowledge. Findings showed that $62.8 \%$ of the participants were using media during their daily work life (Table 2). 
Table 2 Reproductive and Service Related Characteristics of the Participants

\begin{tabular}{|c|c|c|}
\hline Characteristics & $\mathbf{n}$ & $\%$ \\
\hline \multicolumn{3}{|l|}{ Resume of menstruation } \\
\hline Yes & 184 & 43.1 \\
\hline No & 243 & 56.9 \\
\hline \multicolumn{3}{|l|}{ Number of children } \\
\hline I & 206 & 48.2 \\
\hline 2 & 132 & 30.9 \\
\hline 3 & 52 & 12.2 \\
\hline 4 & 18 & 4.2 \\
\hline 5 & 19 & 4.4 \\
\hline \multicolumn{3}{|l|}{ Past family planning use } \\
\hline Yes & 187 & 43.8 \\
\hline No & 240 & 56.2 \\
\hline \multicolumn{3}{|l|}{ Future intention for child } \\
\hline Want to have another child & 158 & 37.0 \\
\hline Not want to have another child & 156 & 36.5 \\
\hline Not decided or do not know & 90 & 21.1 \\
\hline Cannot be pregnant again & 23 & 5.4 \\
\hline \multicolumn{3}{|l|}{ Did $A N C^{a}$ checkup } \\
\hline Yes & 398 & 93.2 \\
\hline No & 29 & 6.8 \\
\hline \multicolumn{3}{|l|}{ Received family planning counseling } \\
\hline Yes & 224 & 56.3 \\
\hline No & 174 & 43.7 \\
\hline \multicolumn{3}{|l|}{ Did $\mathrm{PNC}^{\mathrm{b}}$ checkup } \\
\hline Yes & 211 & 49.4 \\
\hline No & 216 & 50.6 \\
\hline \multicolumn{3}{|l|}{ Received family planning counseling } \\
\hline Yes & 127 & 60.2 \\
\hline No & 84 & 39.8 \\
\hline \multicolumn{3}{|l|}{ Knowledge on FPc methods } \\
\hline Good & 181 & 42.4 \\
\hline Satisfactory & $|5|$ & 35.4 \\
\hline Poor & 95 & 22.2 \\
\hline \multicolumn{3}{|l|}{ Use of media } \\
\hline Yes & 268 & 62.8 \\
\hline No & 159 & 37.2 \\
\hline
\end{tabular}

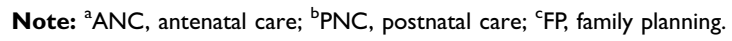

\section{Postpartum Family Planning Utilization}

Among the postpartum mothers, 32.8\% (CI: 0.3-0.4) were using family planning methods. Among the different family planning methods used by the postpartum mother, $37.1 \%$ of the women's husbands were using condoms, $29.3 \%$ of the participants were using DepoProvera and $20 \%$ were using Pills to avoid pregnancy in near future. Similarly, $2.9 \%$ of the mothers had done tubectomy and similar percent $(2.9 \%)$ of the women's husband had done vasectomy after their recent childbirth. About two-thirds (67.2\%) of the postpartum mothers were not using any form of family planning methods. Major reasons for not using any kind of family planning methods were explored in which two-fourth $(40.5 \%)$ of the participants reported their husband is not at home, $23.1 \%$ of the postpartum mother did not feel necessary to use FP methods in this period, $10.5 \%$ reported fear of side effect and $10.2 \%$ of the mothers reported not resuming sex as a reason while $6.8 \%$ mentioned husband disapproval for not using any form of FP methods (Table 3).

\section{Unmet Need for Family Planning Among Postpartum Mother}

The study showed that within the first year of postpartum, $50 \%(\mathrm{CI}=0.4-0.6)$ have an unmet need for $\mathrm{FP}, 38.2 \%$ are using a method of FP, and $11.5 \%$ women want another child after one year of their recent pregnancy. The unmet need for spacing was $24.2 \%$ and the unmet need for limiting was $25.8 \%$ among the mothers during the postpartum period (Figure 1).

Table 3 Postpartum Family Planning Utilization

\begin{tabular}{|l|l|l|}
\hline Characteristics (n=427) & $\mathbf{n}$ & $\%$ \\
\hline Using FP' methods & & \\
Yes & 140 & 32.8 \\
No & 287 & 67.2 \\
\hline Methods used & & \\
Condom & 52 & 37.1 \\
Depo-Provera & 41 & 29.3 \\
Pills & 28 & 20.0 \\
IUCD & 9 & 6.4 \\
Vasectomy & 4 & 2.9 \\
Minilap/Laparoscopy/Tubectomy & 4 & 2.9 \\
Implant & 2 & 1.4 \\
\hline Reason for not using FP ${ }^{\text {a }}$ methods (Multiple responses) & & \\
Husband is migrated & 119 & 40.5 \\
Not felt necessary & 68 & 23.1 \\
Fear of side effect & 31 & 10.5 \\
Sex not resume & 30 & 10.2 \\
Husband disapproval & 20 & 6.8 \\
Others* & 50 & 17.1 \\
Do not now & 27 & 9.2 \\
\hline
\end{tabular}

Notes: *Costly, Method not available, Lack of trained Health Workers, want pregnant again, Do not know the method, Far service site and Family disapproval; ${ }^{a} \mathrm{FP}$, family planning; ${ }^{\mathrm{b}} \mathrm{UUCD}$, intrauterine contraceptive device. 


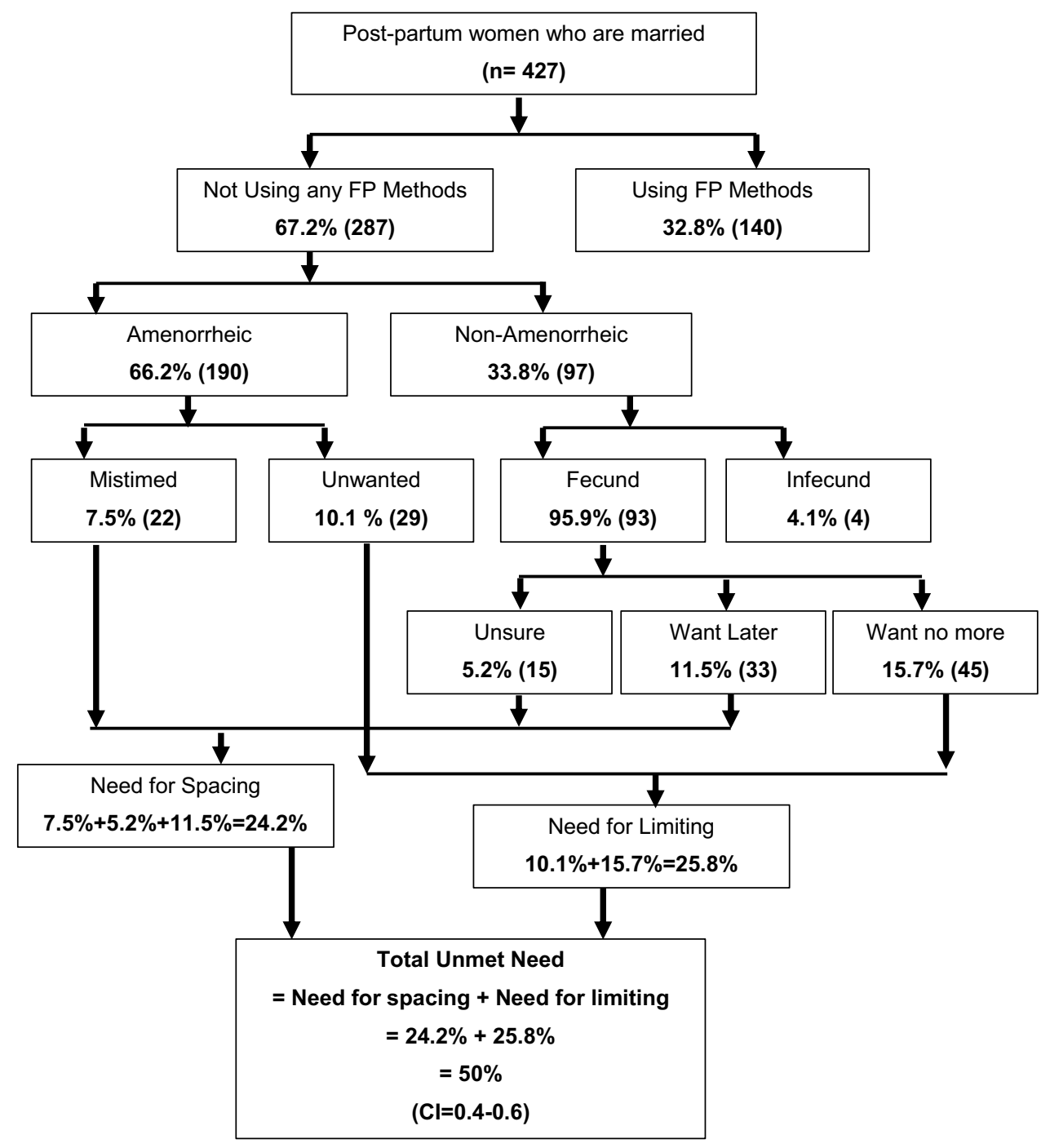

Figure I Unmet need for family planning among postpartum mothers.

\section{Factors Associated with Postpartum Family Planning Utilization}

In the bi-variate analysis, factors found to affect FP methods use among postpartum women were being Janjati ethnic women (crude odds ratio [COR]: 3.2, 95\% CI: 1.6-6.1), having secondary level education (COR: 2.6, 95\% CI: 1.2-5.4), being working women (COR: 1.7, 95\% CI: 1.1-2.6), husband's occupation (COR: 4.0, 95\% CI: 2.4-6.6), higher education level of husband (COR: 2.8 , 95\% CI: 1.0-7.8), resume of menstruation (COR: 3.2, 95\% CI: 2.1-4.9), a good level of knowledge about family planning methods (COR: 2.1, 95\% CI: 1.2-3.7), women who used family planning in the past (COR: 4.9, 95\% CI: 3.2-7.7), use of media (COR: 1.6, 95\% CI: 1.0-2.5), received ANC counseling (COR: 3.2, 95\% CI: 2.0-5.1), had PNC visit (COR: 2.2, 95\% CI: 1.4-3.3) and who received PNC counseling (COR: 2.1, 95\% CI: 1.2-3.7) (Table 4).

In the multivariate analysis, the occupation of the husband, past use of family planning methods, and resumption of menstruation were found to be the strong predictor of family planning utilization among postpartum mothers. Occupation of husband showed significant association with utilization of postpartum family planning methods with an adjusted odds ratio of 3.2 (95\% CI: 2.0-6.0). Women who used family planning methods in the past were significantly more likely to use contraceptives than those who did not use (AOR: 4.0, 95\% CI: 2.4-6.5). Similarly, the mothers who had their menstruation resumed were significantly more likely (AOR: 2.5, 95\% CI: 1.6-4.1) to use family planning methods during the 
Table 4 Factors Associated with Postpartum Family Planning Utilization

\begin{tabular}{|c|c|c|c|c|}
\hline \multirow{2}{*}{$\begin{array}{l}\text { Socio-Demographic Characteristics } \\
\text { Ethnicity }\end{array}$} & \multicolumn{2}{|c|}{ Postpartum Family Planning Method Utilization ${ }^{a}$} & \multirow{5}{*}{$\begin{array}{l}\operatorname{COR}^{\mathbf{d}}\left(95 \% \mathbf{C I}^{\mathbf{e}}\right) \\
1 \\
3.2(1.6-6.1) \\
1.3(0.5-2.9)\end{array}$} & \multirow{5}{*}{$\operatorname{AOR}^{\mathrm{f}}\left(95 \% \mathrm{Cl}^{\mathrm{e}}\right)$} \\
\hline & No (\%) & Yes (\%) & & \\
\hline Dalit* & $57(82.6)$ & $12(17.4)$ & & \\
\hline Janjatis & $169(60.1)$ & $112(39.9)$ & & \\
\hline Other ethnic group ${ }^{b}$ & $61(79.2)$ & $16(20.8)$ & & \\
\hline \multicolumn{5}{|l|}{ Education of participants } \\
\hline Illiterate* & $49(77.8)$ & $14(22.2)$ & $\mathrm{I}$ & - \\
\hline General read and write & $54(59.3)$ & $37(40.7)$ & $2.4(1.2-5.0)$ & \\
\hline Primary schooling & $100(75.2)$ & $33(24.8)$ & $1.2(0.6-2.4)$ & \\
\hline Secondary schooling & $45(57.7)$ & $33(42.3)$ & $2.6(1.2-5.4)$ & \\
\hline $\mathrm{SLC}^{\mathrm{g}}$ and above & $39(62.9)$ & $23(37.1)$ & $2.1(0.9-4.5)$ & \\
\hline \multicolumn{5}{|l|}{ Occupation of participant } \\
\hline Housewives* & 205(70.9) & $84(29.1)$ & I & - \\
\hline Engaged with work & $82(59.4)$ & $56(40.6)$ & $1.7(1.1-2.6)$ & \\
\hline \multicolumn{5}{|l|}{ Husband occupation } \\
\hline Migrant worker** & $130(84.4)$ & $24(15.6)$ & I & 1 \\
\hline Others ${ }^{c}$ & $58(52.7)$ & $52(47.3)$ & $4.0(2.4-6.6)$ & $3.2(2.0-6.0)$ \\
\hline \multicolumn{5}{|l|}{ Husband education } \\
\hline Illiterate* & $24(80.0)$ & $6(20.0)$ & I & - \\
\hline $\mathrm{SLC}^{g}$ and above & $37(58.7)$ & $26(4 \mid .3)$ & $2.8(1.0-7.8)$ & \\
\hline \multicolumn{5}{|l|}{ Resume of menstruation } \\
\hline No** & $190(78.2)$ & $53(21.8)$ & I & 1 \\
\hline Yes & $97(52.7)$ & $87(47.3)$ & $3.2(2.1-4.9)$ & $2.5(1.6-4.1)$ \\
\hline \multicolumn{5}{|l|}{ Knowledge of FPh methods } \\
\hline Poor** & 75 (78.9) & $20(2 I .1)$ & 1 & - \\
\hline Good & $212(63.9)$ & $120(36.1)$ & $2.1(1.2-3.7)$ & \\
\hline \multicolumn{5}{|l|}{ Past family planning use } \\
\hline No** & $197(82.1)$ & $43(17.9)$ & I & I \\
\hline Yes & $90(48.1)$ & $97(51.9)$ & $4.9(3.2-7.7)$ & $4.0(2.4-6.5)$ \\
\hline \multicolumn{5}{|l|}{ Use of media } \\
\hline No* & 117 (73.6) & $42(26.4)$ & I & - \\
\hline Yes & $170(63.4)$ & $98(36.6)$ & $1.6(1.0-2.5)$ & \\
\hline \multicolumn{5}{|l|}{ ANC' counseling received } \\
\hline No** & 139 (79.9) & $35(20.1)$ & 1 & - \\
\hline Yes & $124(55.4)$ & $100(44.6)$ & $3.2(2.0-5.1)$ & \\
\hline \multicolumn{5}{|l|}{ PNC visit done } \\
\hline No** & $163(75.5)$ & $53(24.5)$ & I & - \\
\hline Yes & $124(58.8)$ & $87(4 \mid .2)$ & $2.2(1.4-3.3)$ & \\
\hline \multicolumn{5}{|l|}{$\mathrm{PNC}^{\jmath}$ counseling received } \\
\hline No* & $58(69.0)$ & $26(31.0)$ & I & - \\
\hline Yes & $66(52.0)$ & $61(48.0)$ & $2.1(1.2-3.7)$ & \\
\hline
\end{tabular}

Notes: *p value <0.05; **p value <0.0I; ${ }^{*}$ post-partum family planning methods include all modern methods of Family planning including method mix (Condom, Pills, Depo,

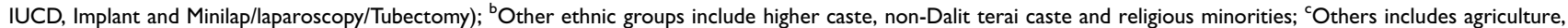
self-employed and service; ${ }^{\mathrm{d}} \mathrm{COR}$, Crude odds ratio; ${ }^{\mathrm{e}} \mathrm{Cl}$, confidence interval; ${ }^{\mathrm{f}} \mathrm{AOR}$, adjusted odds ratio; ${ }^{\mathrm{g}} \mathrm{SLC}$, school leaving certificate; ${ }^{\mathrm{h}} \mathrm{FP}$, family planning; 'ANC- antenatal care; JPNC, postnatal care.

Abbreviations: PPFP, postpartum family planning; FP, family planning; SPSS, Statistical Package for Social Sciences; VDCs, Village Development Committees; CMC-IRC, Chitwan Medical College Ethical Review Committee; ANC, antenatal care; PNC, postnatal care; IDHS, Indonesia Demographic and Health Survey; NDHS, Nepal Demographic Health Survey; PMA, performance monitoring and accountability. 
postpartum period compared to those mothers whose menstruation was not resumed (Table 4).

\section{Discussion}

This is a community based cross-sectional study in an attempt to assess the utilization of family planning methods and associated factors among postpartum mothers. In this study, about one-third (32.8\%) of the participants reported using modern family planning methods during the extended postpartum period. This finding is consistent with similar studies done in Ethiopia and Uganda. ${ }^{11,12}$ However, the finding was higher than the national figure $(22 \%)$ as many of them were placing too much confidence in breastfeeding to prevent pregnancy - even when nonexclusive $^{13}$ and lower than the study conducted in India. ${ }^{14}$

Utilization of Postpartum family planning was significantly associated with past use of family planning methods, occupation of the husband, and resumption of menstruation. The present study revealed that mothers who used family planning methods in the past were significantly more likely to initiate postpartum contraceptive compared to those women who did not use. This is consistent with the study conducted in Ghana which showed past experience of utilizing family planning significantly affect the postpartum family planning use (OR:3.06, 95\% CI:1.71-5.47). ${ }^{9}$ Similar findings of past use of family planning methods being associated with postpartum family planning were presented in studies conducted in Ethiopia ${ }^{15}$ and rural Uganda. ${ }^{16}$ This could be attributed to the fact that women who have previously used family planning methods might have more knowledge, better attitude, and practice regarding the use of the methods and are more likely to adopt the methods during the postpartum period compared to those who have not used in the past.

The results indicated a direct relationship between the occupations of the husband and the utilization of postpartum family planning (PPFP). The possible reason behind this maybe most of the participants were found to be migrant workers and as they are out of their homes for work, women may not feel necessary to use any family planning methods.

The study showed that resumption of menstruation was significantly associated with the postpartum family planning use. This finding is also supported by other studies done in Kenya and Tanzania. ${ }^{17,18}$

Other variables like ethnicity, educational level, occupation of the participants, husband's educational level, knowledge of family planning methods, use of media, ANC counseling, PNC visit and PNC counseling were associated with utilization family planning methods among postpartum mothers in the bi-variate analysis but no significant association was observed in the multivariate analysis.

The study revealed that the unmet need for family planning of postpartum women was $50.0 \%$ with $24.2 \%$ for spacing and $25.8 \%$ for limiting. The rate of unmet need found in this study was similar to the national figure (52\%) which was based on the analysis of data from the Nepal Demographic Health Survey (NDHS) 2011. ${ }^{8}$ The analyses of data from the 2007 and 2012 Indonesia Demographic and Health Surveys (IDHS) and the 2015 PMA 2020 survey however reported total unmet need ranging from $23 \%$ to $28 \%$ which is lower compared to the findings from our study. ${ }^{19}$ Lower rates of unmet need in comparison to our study were also reported by the studies conducted in Ethiopia ${ }^{20}$ and Egypt. ${ }^{21}$

The most popular modern contraceptive methods used by postpartum women were condoms (37.1\%), DepoProvera $(29.3 \%)$ and pills $(20.0 \%)$. This indicates that there was a skewed methods mix of postpartum women. This can be explained in light of women's preferences regarding contraceptive choice and health worker's attitudes toward contraceptive methods. This is in line with a study conducted among postpartum women attending Kathmandu Medical College and 2011 report by the Nepal Demographic Health Survey. ${ }^{22,23}$

Knowledge of contraceptive methods is nearly universal among study participants. Nearly two-thirds of the participants had a good knowledge of modern contraceptive methods this suggests that knowledge of contraceptive methods has not yet been translated into contraceptive practice. This is consistent with the 2016 Nepal Demography Health Survey report. ${ }^{24}$

\section{Strengths and Limitations}

This study has some strengths and limitations that should be noted. The study tried to include possible determinants of contraceptive utilization among postpartum mothers but may not have covered cultural related factors. This study tried to include women from different socio-demographic backgrounds. This study is one of the steps for the improvement of the national family planning program by providing the factors that are affecting the utilization of family planning methods by special groups of postpartum women.

\section{Conclusions}

Contraceptive use among postpartum mothers was found to be low which may increase the risk of unintended pregnancies posing health risks to the mothers. Husband's 
occupation, past use of family planning methods, and resumption of menstruation were important predictors of utilization of family planning methods among postpartum mothers found in this study. Therefore, the Family Planning program should work on improving couples' knowledge of the risk of pregnancy, fertility returning time and modern contraceptives use during the postpartum period. In addition, PPFP messaging should target a large number of women whose husbands are in migrant occupations, who are not menstruating and who have not used FP before to increase uptake of postpartum contraceptive use.

\section{Acknowledgments}

We would like to acknowledge all the participants who participated in this study.

\section{Disclosure}

The authors declare no conflict of interest.

\section{References}

1. UNFPA. Family planning for health and development. 2009.

2. Cates W, Karim QA, El-Sadr W, et al. Family planning and the millennium development goals. Science. 2010;329(5999):1603. doi: $10.1126 /$ science. 1197080

3. WHO. Programming strategies for postpartum family planning. 2013.

4. DaVanzo J, Hale L, Razzaque A, Rahman M. Effects of interpregnancy interval and outcome of the preceding pregnancy on pregnancy outcomes in Matlab, Bangladesh. BJOG. 2007;114(9):1079-1087. doi:10.1111/j.1471-0528.2007.01338.x

5. Puri MC, Maharjan M, Pearson E, et al. Delivering postpartum family planning services in Nepal: are providers supportive? BMC Health Serv Res. 2018;18:1-9.

6. Ackerson K, Zielinski R. Factors influencing use of family planning in women living in crisis affected areas of Sub-Saharan Africa: a review of the literature. Midwifery. 2017;54:35-60. doi:10.1016/j.midw.2017.07. 021

7. Cleland J, Bernstein S, Ezeh A, Faundes A, Glasier A, Innis J. Family planning: the unfinished agenda. Lancet. 2006;368(9549):1810-1827. doi:10.1016/S0140-6736(06)69480-4

8. Mehata S, Paudel YR, Mehta R, Dariang M, Poudel P, Barnett S. Unmet need for family planning in Nepal during the first two years postpartum. Biomed Res Int. 2014;2014:1-9. doi:10.1155/2014/649567

9. Eliason S, Baiden F, Quansah-Asare G, Graham-Hayfron Y, Bonsu D. Factors influencing the intention of women in rural Ghana to adopt postpartum family planning. Reprod Health. 2013;10:34. doi:10.1186/ $1742-4755-10-34$
10. Dasanayake DL, Dilhani BW. Knowledge, attitudes and practices regarding modern methods of postpartum contraception among postnatal mothers. Galle Med J. 2018;23(1):1-6. doi:10.4038/gmj.v23i1. 7983

11. Dona A, Abera M, Alemu T, Hawaria D. Timely initiation of postpartum contraceptive utilization and associated factors among women of child bearing age in Aroressa District, Southern Ethiopia: a community based cross-sectional study. BMC Public Health. 2018;18(1):1100. doi:10.1186/s12889-018-5981-9

12. Rutaremwa G, Kabagenyi A, Wandera SO, Jhamba T, Akiror E, Nviiri HL. Predictors of modern contraceptive use during the postpartum period among women in Uganda: a population-based cross sectional study. BMC Public Health. 2015;15(1):262. doi:10.1186/ s12889-015-1611-y

13. MN E. Nepal demographic and health survey 2006. 2007.

14. Mahmood SE, Srivastava A, Shrotriya VP, Shaifali I, Mishra P. Postpartum contraceptive use in rural Bareilly. Indian J Community Health. 2011;23(2):56-57.

15. Gebremedhin AY, Kebede Y, Gelagay AA, Habitu YA. Family planning use and its associated factors among women in the extended postpartum period in Addis Ababa, Ethiopia. Contracept Reprod Med. 2018;3(1):1. doi:10.1186/s40834-017-0054-5

16. Sileo KM, Wanyenze RK, Lule H, Kiene SM. Determinants of family planning service uptake and use of contraceptives among postpartum women in rural Uganda. Int J Public Health. 2015;60(8):987-997. doi:10.1007/s00038-015-0683-x

17. Keogh S, Urassa M, Kumogala Y, Zaba B. Dynamics of postpartum contraceptive use, and their relationship to antenatal intentions in Northern Tanzania. Stud Fam Plann. 2015;46:405-422.

18. Ndugwa RP, Cleland J, Madise NJ, Fotso J-C, Zulu EM. Menstrual pattern, sexual behaviors, and contraceptive use among postpartum women in Nairobi urban slums. $J$ Urban Health. 2011;88 (2):341-355. doi:10.1007/s11524-010-9452-6

19. Wilopo SA, Setyawan A, Pinandari AW, Prihyugiarto T, Juliaan F, Magnani RJ. Levels, trends and correlates of unmet need for family planning among postpartum women in Indonesia: 2007-2015. BMC Women's Health. 2017;17(1):120. doi:10.1186/ s12905-017-0476-x

20. Embafrash G, Mekonnen W. Level and correlates of unmet need of contraception among women in extended postpartum in Northern Ethiopia. Int J Reprod Med. 2019;2019.

21. Elweshahi HMT, Gewaifel GI, Sadek SSE-D, El-Sharkawy OG. Unmet need for postpartum family planning in Alexandria, Egypt. Alexandria J Med. 2018;54(2):143-147. doi:10.1016/j.ajme.2017. 03.003

22. Bajracharya A. Knowledge, attitude and practice of contraception among postpartum women attending Kathmandu Medical College Teaching Hospital. Kathmandu Univ Med J. 2015;13(4):292-297. doi:10.3126/kumj.v13i4.16826

23. William Winfrey KR. Use of Family Planning in the Postpartum Period. ICF International; 2014:36.

24. Nepal Demographic and Health Survey. 2016.
International Journal of Women's Health

\section{Publish your work in this journal}

The International Journal of Women's Health is an international, peerreviewed open-access journal publishing original research, reports, editorials, reviews and commentaries on all aspects of women's healthcare including gynecology, obstetrics, and breast cancer. The manuscript management system is completely online and includes a very quick and fair peer-review system, which is all easy to use. Visit http://www.dovepress.com/testimonials.php to read real quotes from published authors. 